\title{
Spontaneous Supramolecular Polymerization Driven by Discrete Platinum Metallacycle-Based Host-Guest Complexation
}

Bingbing Shi, ${ }^{*},+$ Zhixuan Zhou, ${ }^{\ddagger}$ Ryan T. Vanderlinden,,${ }^{\ddagger}$ Jian-Hong Tang, ${ }^{\ddagger}$ Guocan Yu, ${ }^{*}{ }^{\S}$ Koushik Acharyya, ${ }^{\ddagger}$ Hajar Sepehrpour, ${ }^{\ddagger}$ and Peter J. Stang*,\$

'Key Laboratory of Eco-Functional Polymer Materials of the Ministry of Education, College of Chemistry and Chemical Engineering, Northwest Normal University, Lanzhou 730070, P. R. China

tDepartment of Chemistry, University of Utah, 315 South 1400 East, Room 2020, Salt Lake City, Utah 84112, United States

${ }^{\S}$ Laboratory of Molecular Imaging and Nanomedicine, National Institute of Biomedical Imaging and Bioengineering, National Institutes of Health, Bethesda, Maryland 20892, United States

E-mail: bingbingshi@nwnu.edu.cn; guocan.yu@nih.gov;stang@chem.utah.edu

\section{Supporting Information (13 pages)}

1. Materials and methods

S2

2. Synthesis of organic ligand 2

S3

3. Preparation of platinum(II) metallacycle $\mathbf{1}$

S8

4. Host-guest complexation of monomer 1 in the solid state

S1 1

5. 2D NOESY NMR spectrum of metallacycle $\mathbf{1}$

S11

6. DLS study of the assemblies of monomer 1

S12

7. Self-assembled single-crystal structure of metallacycle $\mathbf{1}$

S12

8. X-ray crystal data for metallacycle 1

S12

9. References

S13 


\section{Materials and methods}

All reagents were commercially available and used as supplied without further purification. Solvents were either employed as purchased or dried according to procedures described in the literature. ${ }^{1} \mathrm{H}$ NMR and ${ }^{13} \mathrm{C}$ HMR spectra were recorded with a Bruker Avance DMX-600 spectrometer, a Bruker Avance DMX-500 spectrometer or a Bruker Avance III-400 spectrometry using the deuterated solvent as the lock and the residual solvent or TMS as the internal reference. DOSY and NOESY spectra were collected on a Bruker Avance DMX-500 spectrometer with internal standard TMS. The ${ }^{31} \mathrm{P}\left\{{ }^{1} \mathrm{H}\right\}$ NMR chemical shifts are referenced to an external unlocked sample of $85 \% \mathrm{H}_{3} \mathrm{PO}_{4}(\delta 0.0)$. High-resolution mass spectrometric experiments were performed with a Bruker 7-Tesla FT-ICR mass spectrometer equipped with an electrospray source (Billerica, MA, USA). Scanning electron microscopy investigations were carried out on a JEOL 6390LV instrument. Transmission electron microscopic investigations were carried out on a HITACHI HT-7700 instrument. Dynamic light scattering was carried out on a Malvern Nanosizer S instrument at room temperature.

Single-crystal growth: single crystal growth was performed via the following method: $5.0 \mathrm{mg}$ of dry 1 powder was put in a small vial where $3 \mathrm{~mL}$ of acetone was added. Light-yellow crystal of 1 was obtained by slow diffusion of ether into the acetone solution of 1 in 2 to 3 days.

Dynamic light scattering (DLS) study: the solutions of $1(1.00 \mathrm{M}$ and $60.0 \mathrm{mM})$ were left to stand about 10 min before being used for DLS tests.

Scanning electron microscopy (SEM): the morphologies of the self-assemblies were investigated by SEM which helped in the visualization of the self-assembled structures. SEM samples were prepared by dropcoating acetone solutions containing $1(90.0 \mathrm{mM})$ onto silicon wafers via the vacuum freeze-drying methodology.

Transmission electron microscopy (TEM): the morphologies of the self-assemblies were investigated by TEM which helped in the visualization of the self-assembled structures. TEM samples were prepared by drop-coating acetone solutions containing $1(90.0 \mathrm{mM})$ onto copper grids via the vacuum freeze-drying methodology. 
Scheme S1. Synthetic route to 2.
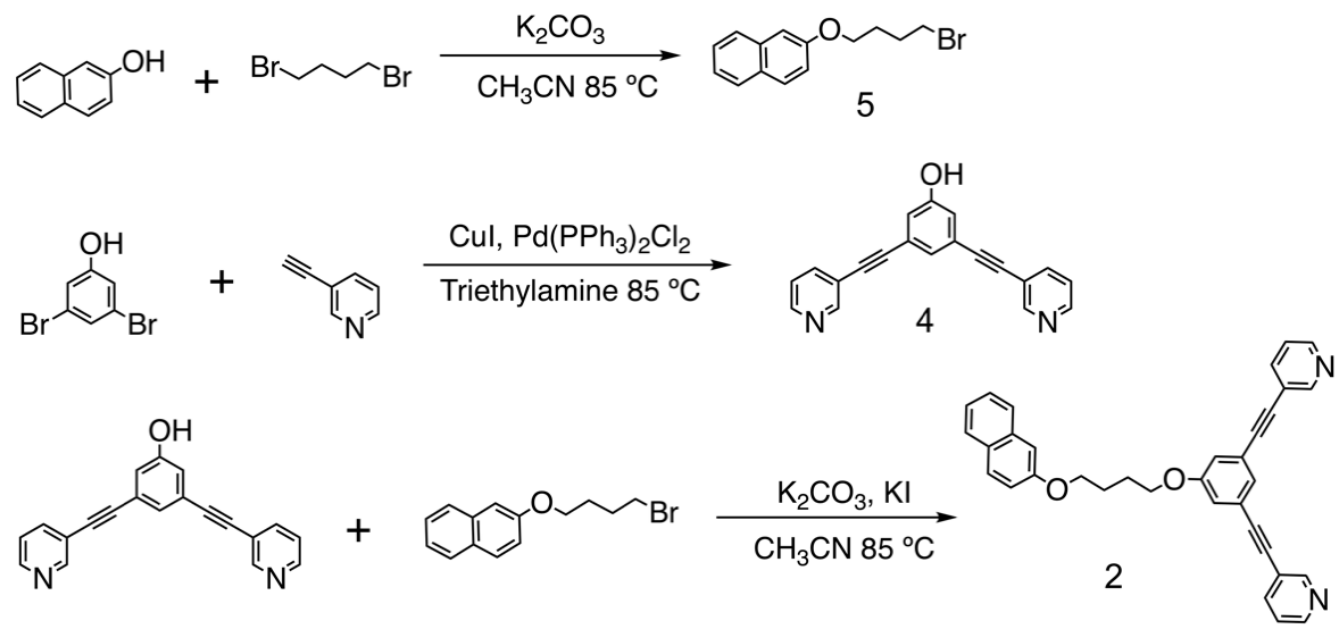

\section{2-(4-Bromobutoxy)naphthalene (5)}

In a $200 \mathrm{~mL}$ round bottom flask, 2-naphthol (1.40 g, $10.0 \mathrm{mmol}), \mathrm{K}_{2} \mathrm{CO}_{3}(5.50 \mathrm{~g}, 40.0 \mathrm{mmol}), 1,4-$ dibromobutane $(4.30 \mathrm{~g}, 20.0 \mathrm{mmol})$ and acetonitrile $(100.0 \mathrm{~mL})$ were added. The reaction mixture was stirred at reflux for 12 hours. After the solid was filtered off, the solvent was removed. The solid was dissolved in $\mathrm{CHCl}_{3}(150 \mathrm{~mL})$ and washed twice with $\mathrm{H}_{2} \mathrm{O}(200 \mathrm{~mL})$. The organic layer was dried over anhydrous $\mathrm{Na}_{2} \mathrm{SO}_{4}$ and evaporated to afford the crude product, which was recrystallized with $\mathrm{CH}_{3} \mathrm{CN}$ to give $2.20 \mathrm{~g}$ of 2-(4-bromobutoxy)naphthalene 5 (yield: $78 \%$ ) as a yellow solid. ${ }^{1} \mathrm{H}$ NMR spectrum of $\mathbf{5}$ is shown in Figure S1. ${ }^{1} \mathrm{H}$ NMR (400 MHz, $\left.\mathrm{CDCl}_{3}, 298 \mathrm{~K}\right) \delta(\mathrm{ppm}): 7.71-7.77(\mathrm{~m}, 3 \mathrm{H}), 7.43$ (t, $J=4 \mathrm{~Hz}$, $1 \mathrm{H}), 7.33(\mathrm{t}, J=4 \mathrm{~Hz}, 1 \mathrm{H}), 7.12-7.15(\mathrm{~m}, 2 \mathrm{H}) .{ }^{13} \mathrm{C}$ NMR spectrum of 3 is shown in Figure S2. ${ }^{13} \mathrm{C}$ NMR $\left(100 \mathrm{MHz}, \mathrm{CDCl}_{3}, 298 \mathrm{~K}\right) \delta$ (ppm): 159.60, 159.46, 137.24, 137.19, 132.05, 132.02, 131.62, 131.59, $130.29,129.35,129.02,128.97,126.26,126.19,121.60,121.51,109.27,109.23,70.12,69.48,36.13$, $32.19,30.53,28.70$.

\section{3,5-Bis(pyridin-3-ylethynyl)phenol (4)}

Compound 4 was prepared according to previously reported procedures. ${ }^{\mathrm{S} 1}$ 3,5-Dibromophenol (2.60 g, $10.0 \mathrm{mmol}), 3$-ethynylpyridine ( $4.10 \mathrm{~g}, 40 \mathrm{mmol}),\left[\mathrm{Pd}\left(\mathrm{PPh}_{3}\right)_{2} \mathrm{Cl}_{2}\right](2.80 \mathrm{~g}, 4.0 \mathrm{mmol})$ and $\mathrm{CuI}(0.80 \mathrm{~g}, 4.0$ mmol) were added to $50.0 \mathrm{~mL}$ of triethylamine and heated under an argon atmosphere at $85^{\circ} \mathrm{C}$. After 72 
hours, the reaction mixture was diluted with ethylacetate $(100 \mathrm{~mL})$ and filtrated over celite. The solvent was removed under reduced pressure and the crude residue was further purified by column chromatography $\left(\mathrm{CH}_{2} \mathrm{Cl}_{2}: \mathrm{MeOH}=20: 1\right)$ to give $1.10 \mathrm{~g}$ of 3,5-bis(pyridin-3-ylethynyl)phenol 4 as an offwhite solid (yield: 38\%). ${ }^{1} \mathrm{H}$ NMR (400 MHz, $\mathrm{CDCl}_{3}, 298 \mathrm{~K}$ ) $\delta$ (ppm): 9.70 (s, 1H), 8.83 (s, 2H), 8.58 (d, $J=4 \mathrm{~Hz}, 2 \mathrm{H}), 7.89$ (d, $J=8 \mathrm{~Hz}, 2 \mathrm{H}), 7.36-7.39$ (m, 2H), 7.29 (d, $J=8 \mathrm{~Hz}, 1 \mathrm{H}), 7.12$ (s, 2H). ${ }^{13} \mathrm{C}$ NMR spectrum of 3 is shown in Figure S2. ${ }^{13} \mathrm{C}$ NMR $\left(100 \mathrm{MHz}, \mathrm{CDCl}_{3}, 298 \mathrm{~K}\right) \delta(\mathrm{ppm}): 151.68,148.14,139.04$, $126.41,123.83,123.54,120.68,119.70,92,22,85.93$.

\section{3,3'-((5-(4-(Naphthalen-2-yloxy)butoxy)-1,3-phenylene)bis(ethyne-2,1-diyl))dipyridine (2)}

In a $200 \mathrm{~mL}$ round-bottom flask, compound $4(1.50 \mathrm{~g}, 5.0 \mathrm{mmol}), \mathrm{K}_{2} \mathrm{CO}_{3}(2.80 \mathrm{~g}, 20 \mathrm{mmol}), \mathrm{KI}(0.20 \mathrm{~g}$, $1.0 \mathrm{mmol})$, compound $5(1.50 \mathrm{~g}, 5.5 \mathrm{mmol})$ and acetonitrile $(100.0 \mathrm{~mL})$ were added. The reaction mixture was stirred at reflux for 12 hours. After the solid was filtered off, the solvent was removed. The solid was dissolved in $\mathrm{CHCl}_{3}(150 \mathrm{~mL})$ and washed twice with $\mathrm{H}_{2} \mathrm{O}(200 \mathrm{~mL})$. The organic layer was dried over anhydrous $\mathrm{Na}_{2} \mathrm{SO}_{4}$ and evaporated to afford the crude product, which was recrystallized with $\mathrm{CH}_{3} \mathrm{CN}$ to give $1.80 \mathrm{~g}$ of 3,3'-((5-(4-(naphthalen-2-yloxy)butoxy)-1,3-phenylene)bis(ethyne-2,1-diyl)) dipyridine 2 (yield: $72 \%$ ) as a yellow solid. ${ }^{1} \mathrm{H}$ NMR spectrum of $\mathbf{2}$ is shown in Figure $\mathrm{S} 5 .{ }^{1} \mathrm{H}$ NMR (600 MHz, $\mathrm{CDCl}_{3}$, $298 \mathrm{~K}) \delta(\mathrm{ppm}): 8.76(\mathrm{~m}, 2 \mathrm{H}), 8.56(\mathrm{~m}, 2 \mathrm{H}), 7.81-7.80(\mathrm{~m}, 2 \mathrm{H}), 7.76-7.70(\mathrm{~m}, 3 \mathrm{H}), 7.42(\mathrm{t}, J=18 \mathrm{~Hz}$, 1H), 7.34-7.29 (m, 4H), 7.15-7.13 (m, 2H), 7.09 (s, 2H), 4.17 (s, 2H), $4.12(\mathrm{~s}, 2 \mathrm{H}), 2.06-2.05$ (t, $J=6$ $\mathrm{Hz}, 4 \mathrm{H}) .{ }^{13} \mathrm{C}$ NMR spectrum of 2 is shown in Figure S6. ${ }^{13} \mathrm{C} \mathrm{NMR}\left(125 \mathrm{MHz}, \mathrm{CDCl}_{3}, 298 \mathrm{~K}\right) \delta(\mathrm{ppm})$ : $161.41,159.52,154.92,151.42,141.17,137.20,132.04,131.59,130.28,130.04,129.34,129.00,126.57$, $126.22,125.72,122.76,121.54,120.94,109.25,94.27,89.06,70.53,69.98,28.60,28.55$. 

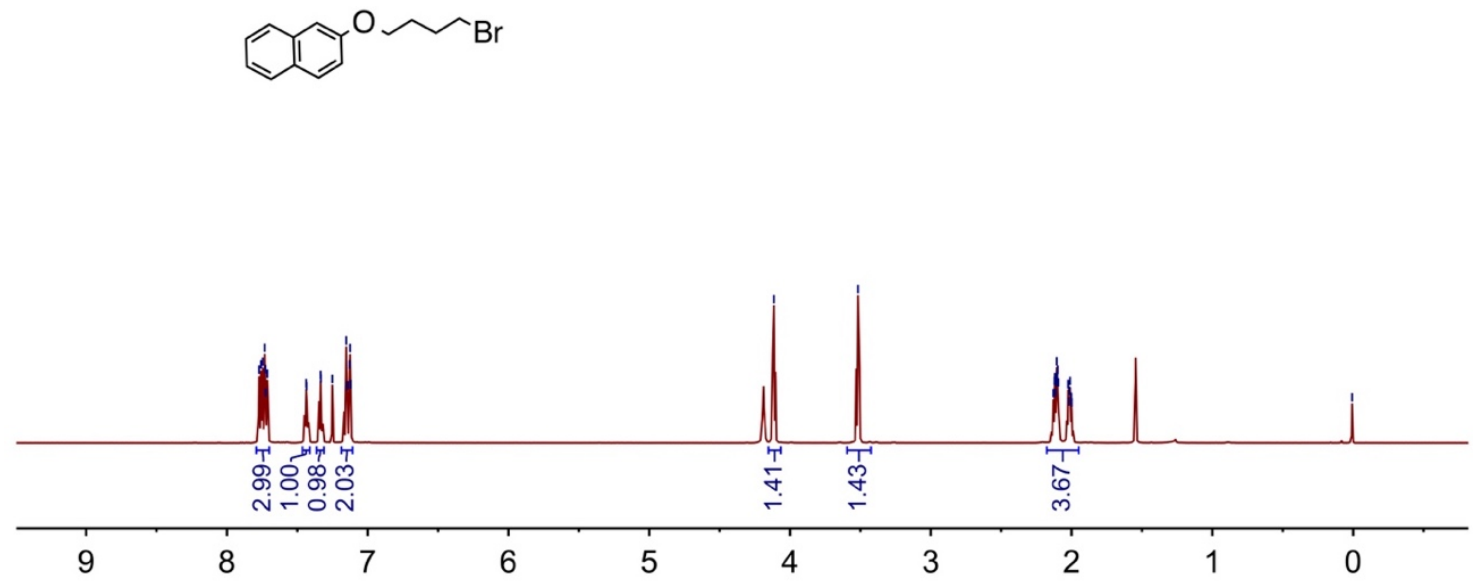

Figure S1. ${ }^{1} \mathrm{H}$ NMR spectrum $\left(400 \mathrm{MHz}, \mathrm{CDCl}_{3}, 298 \mathrm{~K}\right)$ of compound 5.

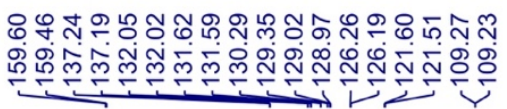

ำ
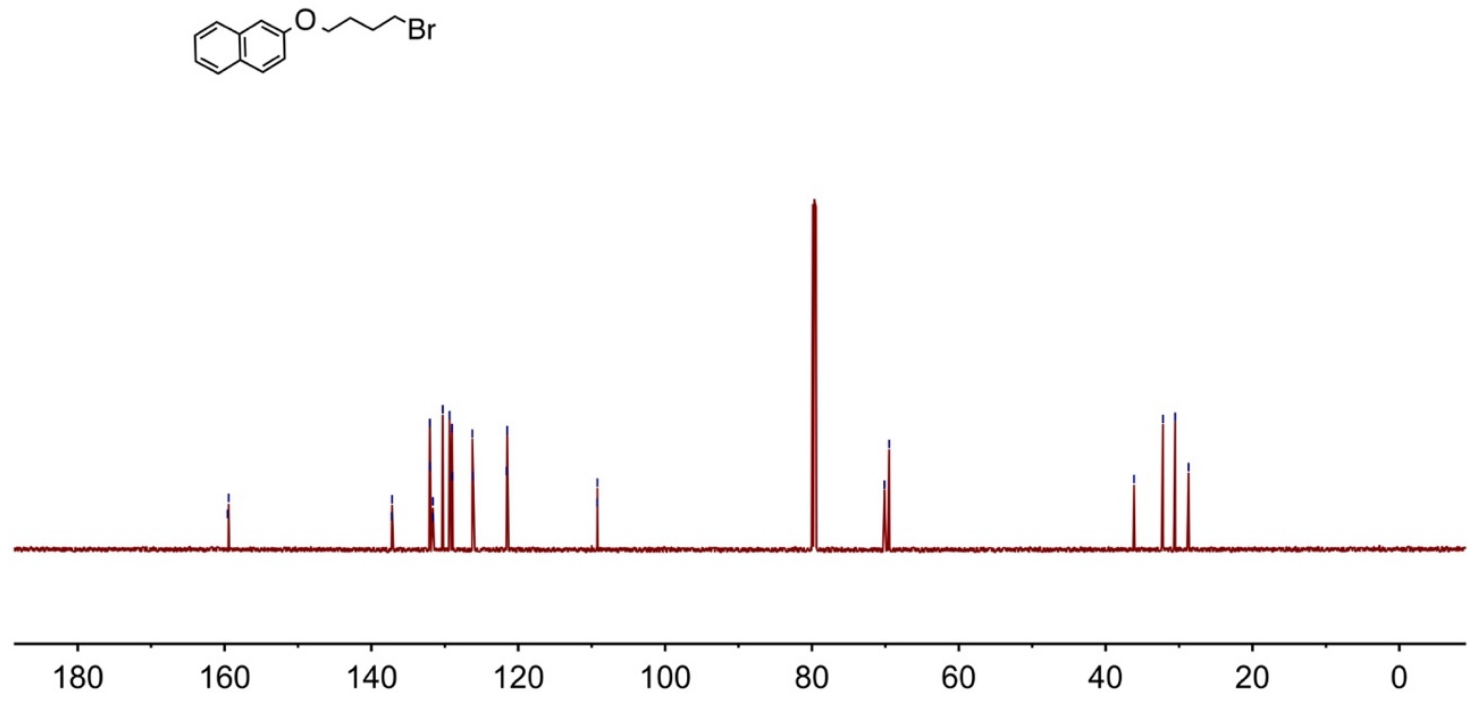

Figure S2. ${ }^{13} \mathrm{C}$ NMR spectrum $\left(400 \mathrm{MHz}, \mathrm{CDCl}_{3}, 298 \mathrm{~K}\right)$ of compound 5 . 

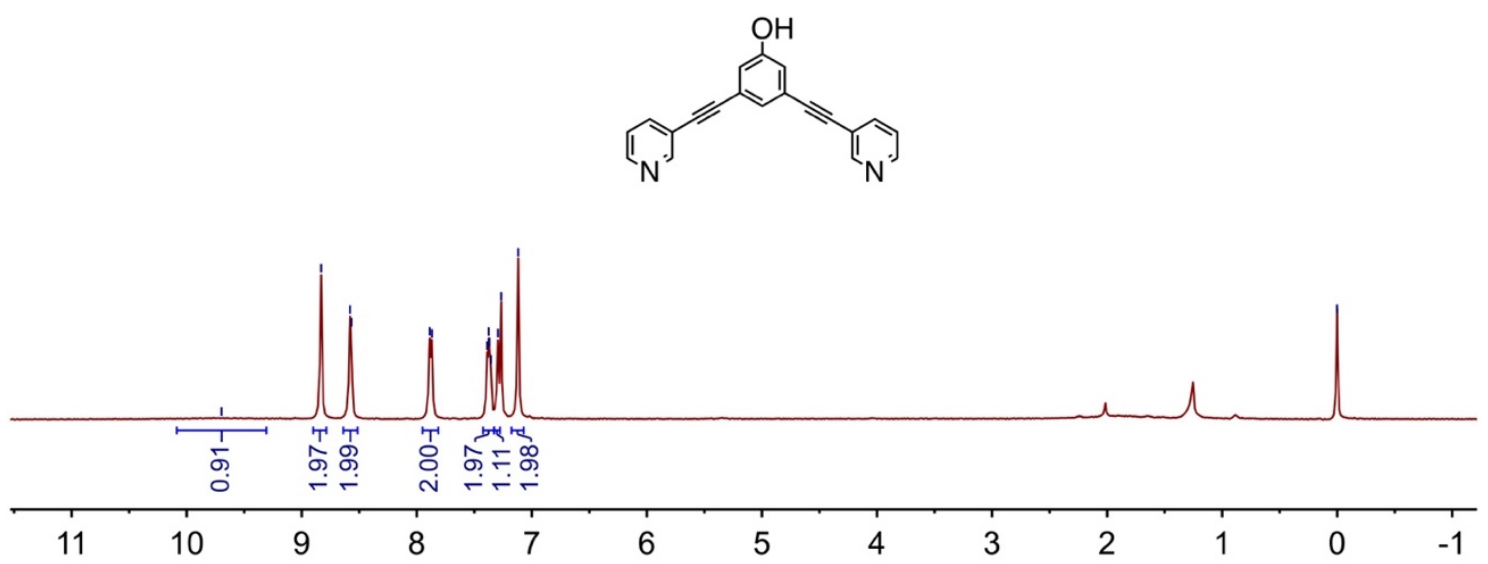

Figure S3. ${ }^{1} \mathrm{H}$ NMR spectrum $\left(400 \mathrm{MHz}, \mathrm{CDCl}_{3}, 298 \mathrm{~K}\right)$ of compound 4.
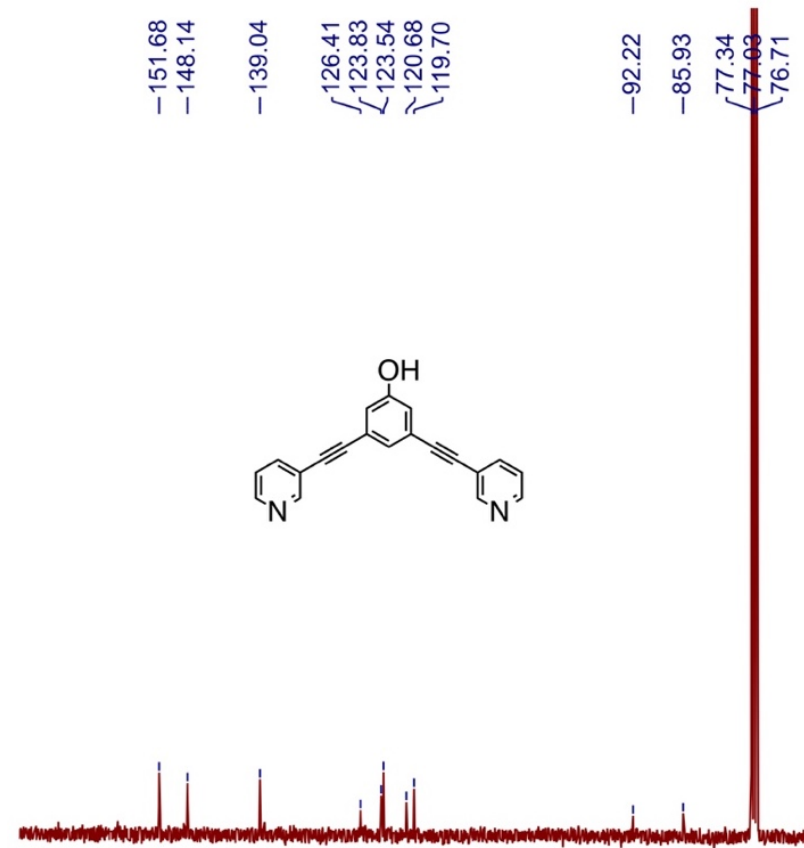

$160 \quad 140$

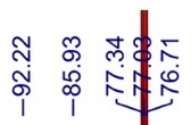

60
20

0

Figure S4. ${ }^{13} \mathrm{C}$ NMR spectrum (400 MHz, $\mathrm{CDCl}_{3}, 298 \mathrm{~K}$ ) of compound 4. 


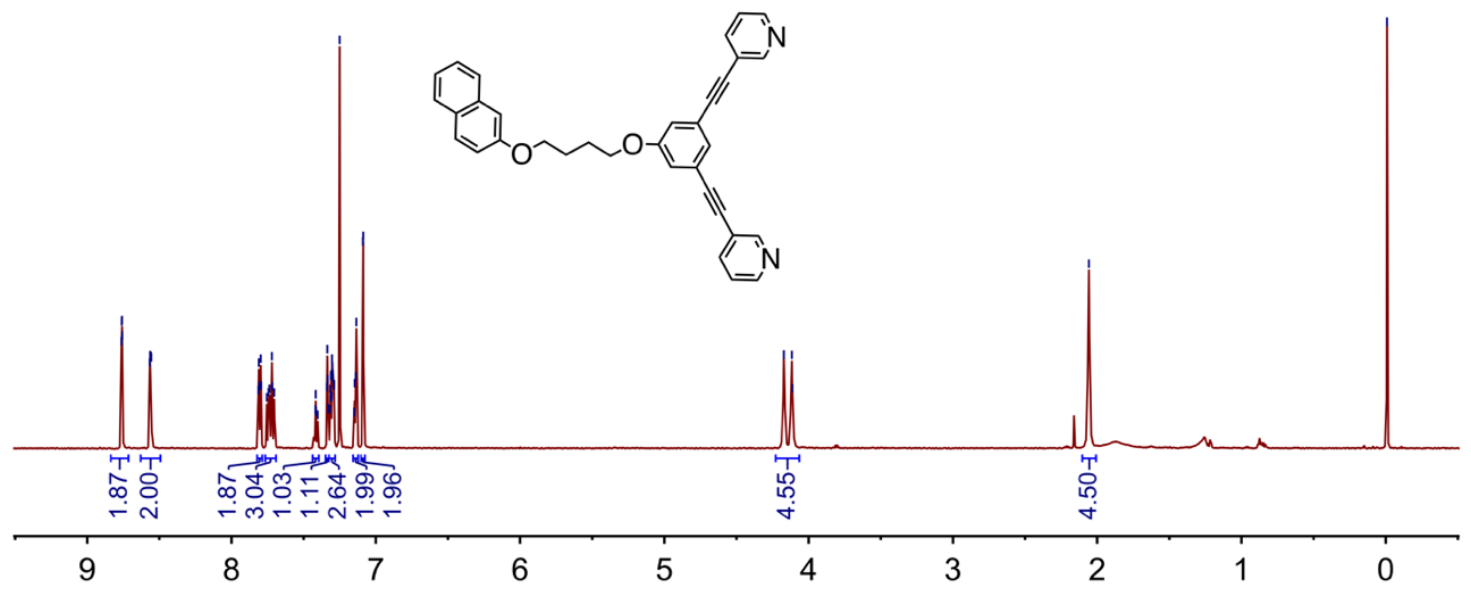

Figure S5. ${ }^{1} \mathrm{H}$ NMR spectrum $\left(600 \mathrm{MHz}, \mathrm{CDCl}_{3}, 298 \mathrm{~K}\right)$ of ligand 2.
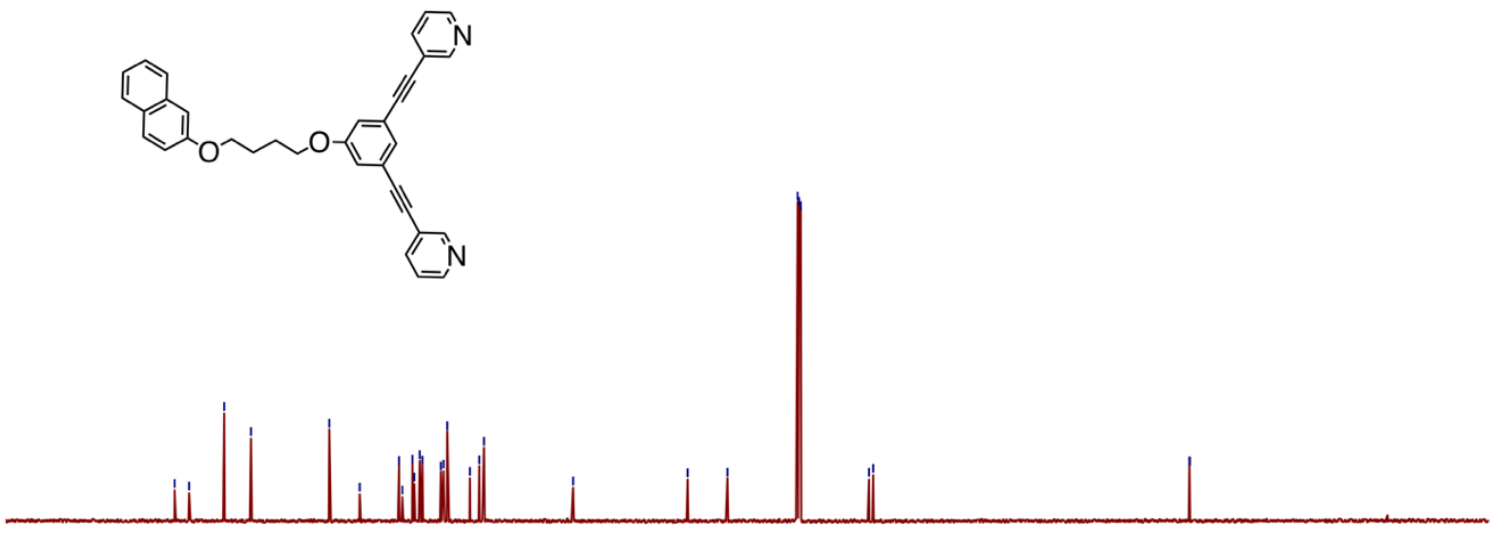

Figure S6. ${ }^{13} \mathrm{C}$ NMR spectrum $\left(600 \mathrm{MHz}, \mathrm{CDCl}_{3}, 298 \mathrm{~K}\right)$ of ligand 2. 


\section{Preparation of platinum(II) metallacycle 1.}

Scheme S2. Preparation of metallacycle 1.

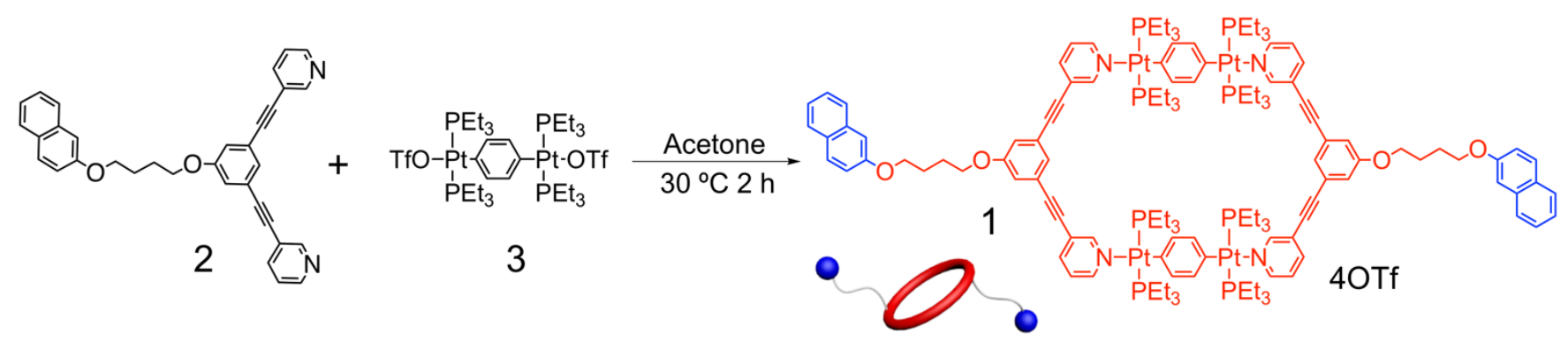

$180^{\circ}$ di-Pt (II) acceptor 3 was prepared according to the literature procedure published before. ${ }^{\mathrm{S} 2}$

\section{Platinum(II) Metallacycle (1)}

Ligand $2(2.97 \mathrm{mg}, 6.00 \mu \mathrm{mol})$ and $180^{\circ}$ organic di-Pt(II) $3(7.42 \mathrm{mg}, 6.00 \mu \mathrm{mol})$ were placed in a 2-dram vial, followed by addition of acetone $(1.00 \mathrm{~mL})$. The mixture was stirred at $30^{\circ} \mathrm{C}$ for 2 hours. Then, all solvent was removed by $\mathrm{N}_{2}$ flow and the solid was dried under vacuum. Acetone $(0.50 \mathrm{~mL})$ was then added into the resultant mixture, and the solution was stirred for $2 \mathrm{~h}$ at room temperature. Then, the mixture was filtered to remove insoluble materials. The resulting metallacycle $\mathbf{1}$ was precipitated with diethyl ether, isolated and dried under reduced pressure and dissolved in deuterated acetone for characterization. ${ }^{1} \mathrm{H}$ NMR spectrum of 1 is shown in Figure S7. ${ }^{1} \mathrm{H}$ NMR (acetone- $\left.d_{6}, 298 \mathrm{~K}, 400 \mathrm{MHz}\right) \delta$ (ppm): 9.22 (s, 4H), 9.05 (d, $J=4 \mathrm{~Hz}, 4 \mathrm{H}), 8.32$ (d, $J=8 \mathrm{~Hz}, 4 \mathrm{H}), 7.89-7.93$ (m, 4H), 7.79-7.84 (m, 6H), 7.43-7.47 (m, 4H), 7.33-7.37 (m, 10H), 7.17-7.20 (m, 4H), 4.25-4.29 (m, 8H), 2.04-2.08 (m, 8H), 1.54$1.56(\mathrm{~m}, 40 \mathrm{H}), 1.18-1.30(\mathrm{~m}, 72 \mathrm{H}) .{ }^{13} \mathrm{C}$ NMR spectrum of $\mathbf{1}$ is shown in Figure S8. ${ }^{13} \mathrm{C}$ NMR (acetone$\left.d_{6}, 298 \mathrm{~K}, 150 \mathrm{MHz}\right) 162.01,159.72,156.54,154.58,144,34,139.42,139.05,137.51,132.31,131.93$, $131.70,130.24,130.19,129.82,129.35,128.94,126.28,126.13,126.08,125.33,123.20,121.88,121.45$, 109.29, 96.26, 87.12, 70.83, 69.98, 34.37, 32.21, 32.09, 29.52, 28.37, 28.33, 25.07, 16.10, 15.10, 14.99, 14.87, 9.79. ${ }^{31} \mathrm{P}\left\{{ }^{1} \mathrm{H}\right\}$ NMR spectrum of $\mathbf{1}$ is shown in Figure $\mathrm{S} 10 .{ }^{31} \mathrm{P}\left\{{ }^{1} \mathrm{H}\right\}$ NMR (acetone- $d_{6}, 298 \mathrm{~K}, 202.3$ MHz) $\delta(\mathrm{ppm}): 12.89\left(\mathrm{~s},{ }^{195} \mathrm{Pt}\right.$ satellites, $\left.J_{\mathrm{Pt}-\mathrm{P}}=3406.73 \mathrm{~Hz}\right)$. TOF-ESI-MS is shown in Figure S10: $\mathrm{m} / \mathrm{z}$ $1004.9906[\mathrm{M}-3 \mathrm{OTf}]^{3+}$. 


$$
-\cdots
$$
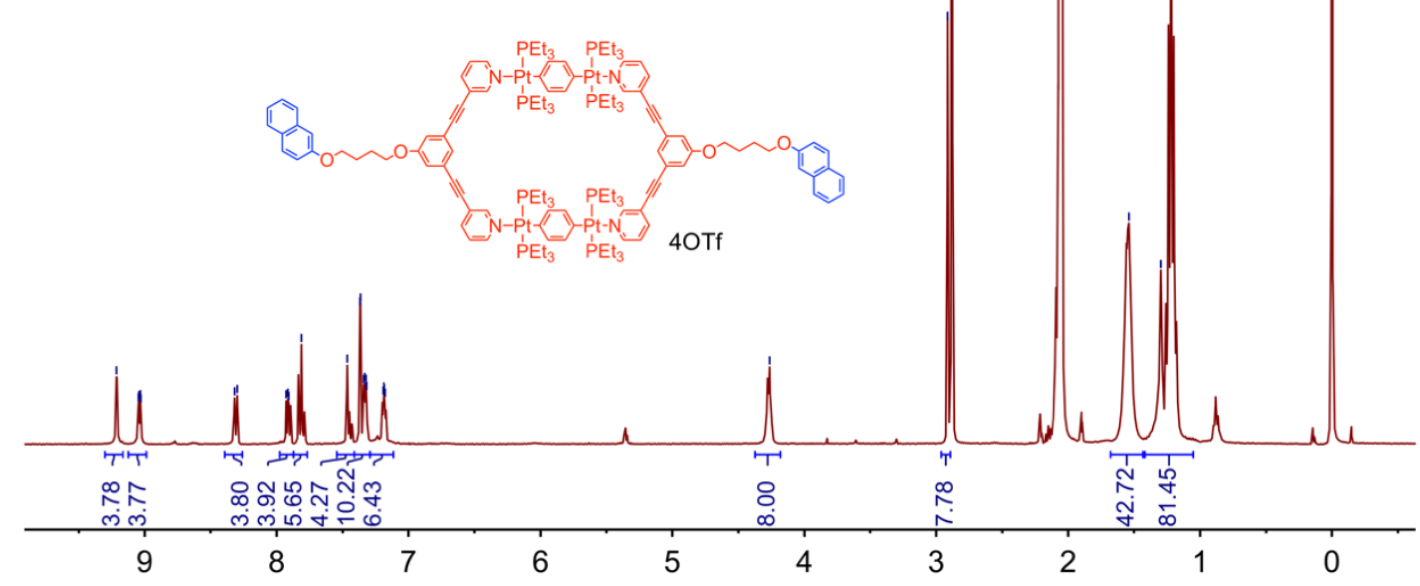

Figure S7. ${ }^{1} \mathrm{H}$ NMR spectrum (400 MHz, acetone- $\left.d_{6}, 298 \mathrm{~K}\right)$ of 1.

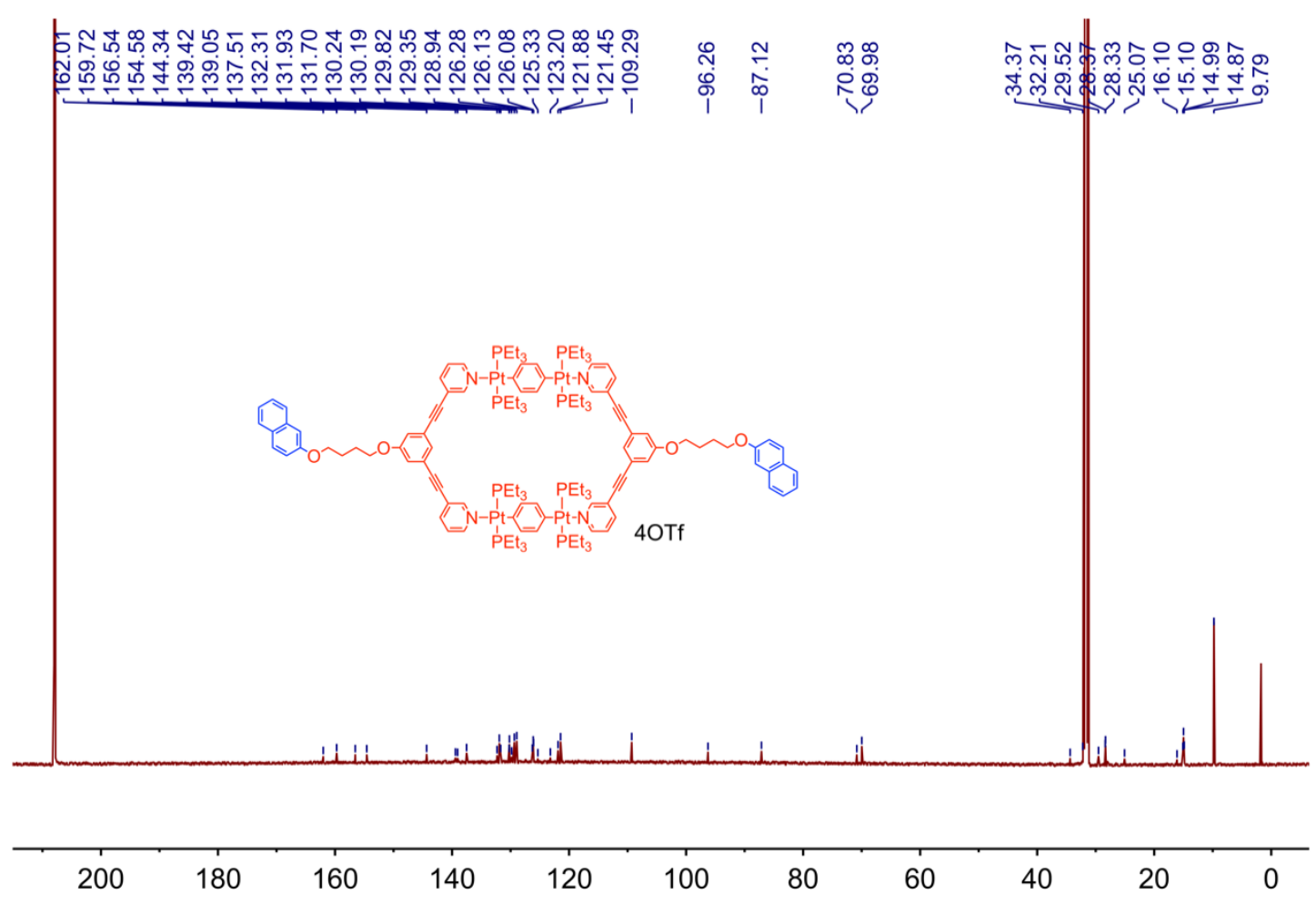

Figure S8. ${ }^{13} \mathrm{C}$ NMR spectrum $\left(600 \mathrm{MHz}\right.$, acetone- $\left.d_{6}, 298 \mathrm{~K}\right)$ of $\mathbf{1}$. 


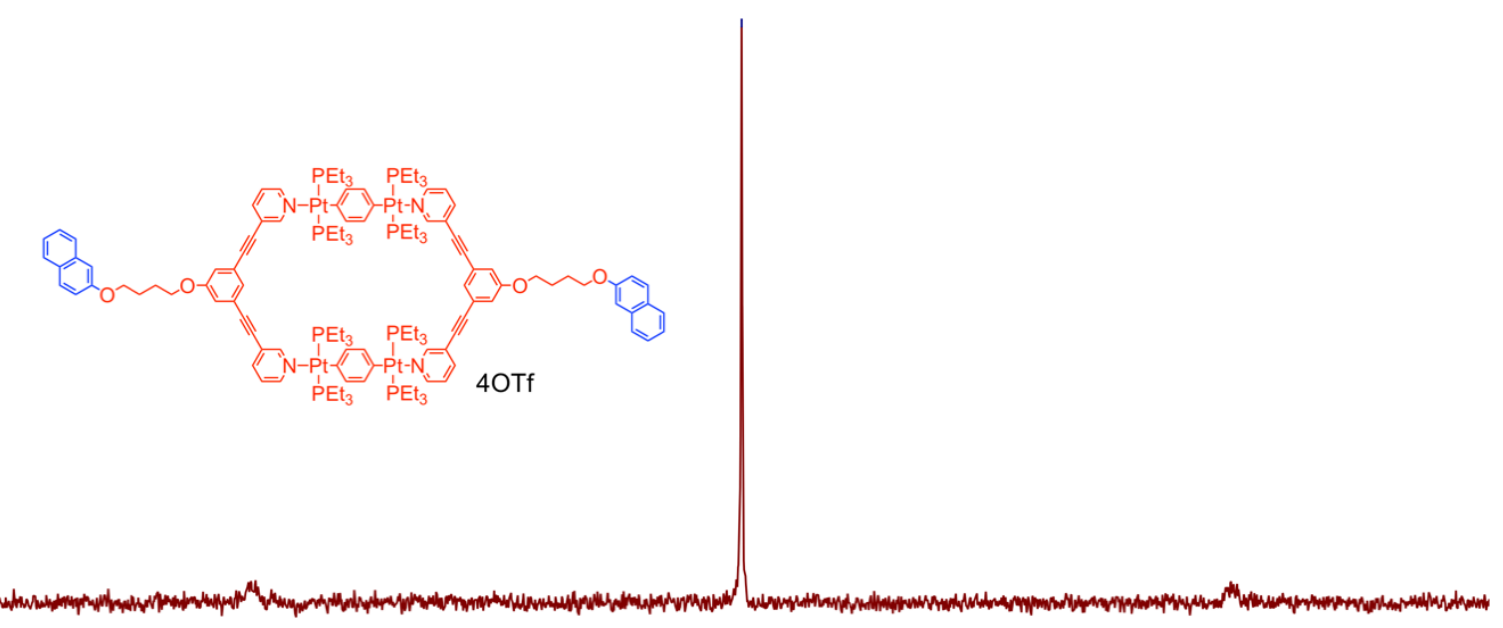

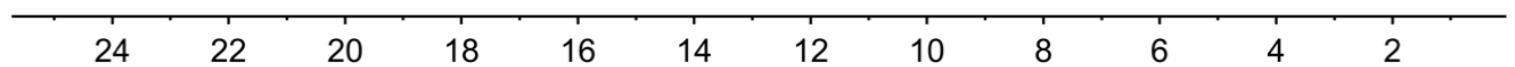

Figure S9. ${ }^{31} \mathrm{P}\left\{{ }^{1} \mathrm{H}\right\}$ NMR spectrum (acetone- $d_{6}, 298 \mathrm{~K}, 202.3 \mathrm{MHz}$ ) of 1.

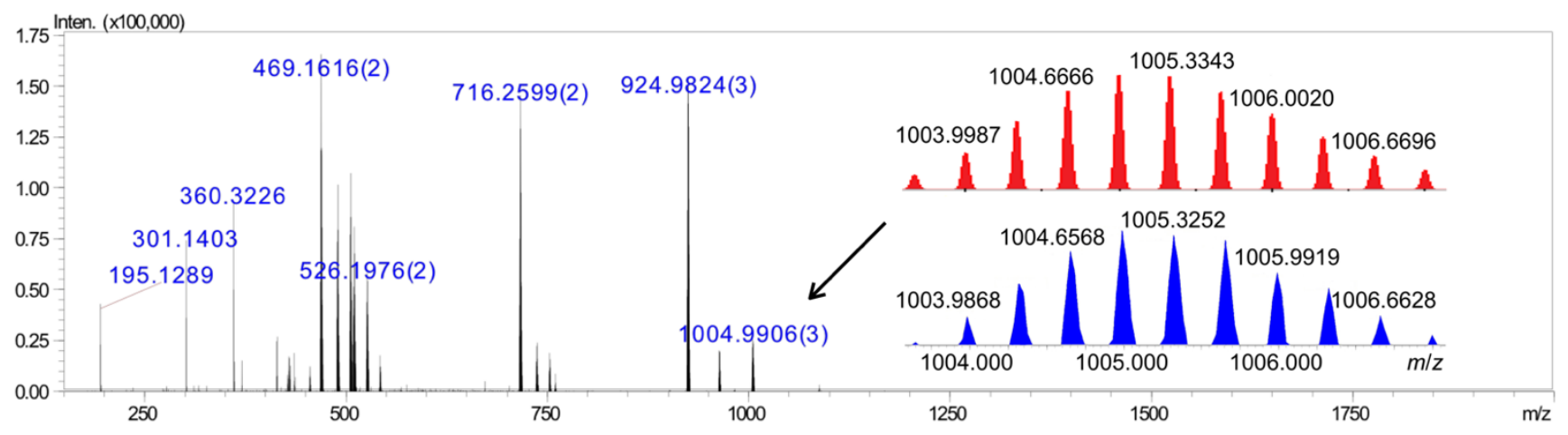

Figure S10. Full ESI-TOF-MS spectrum of 1. Insert: experimental (blue) and calculated (red) electrospray ionization peaks of the $[\mathrm{M}-3 \mathrm{OTf}]^{3+}$ charge state of $\mathbf{1}$. 


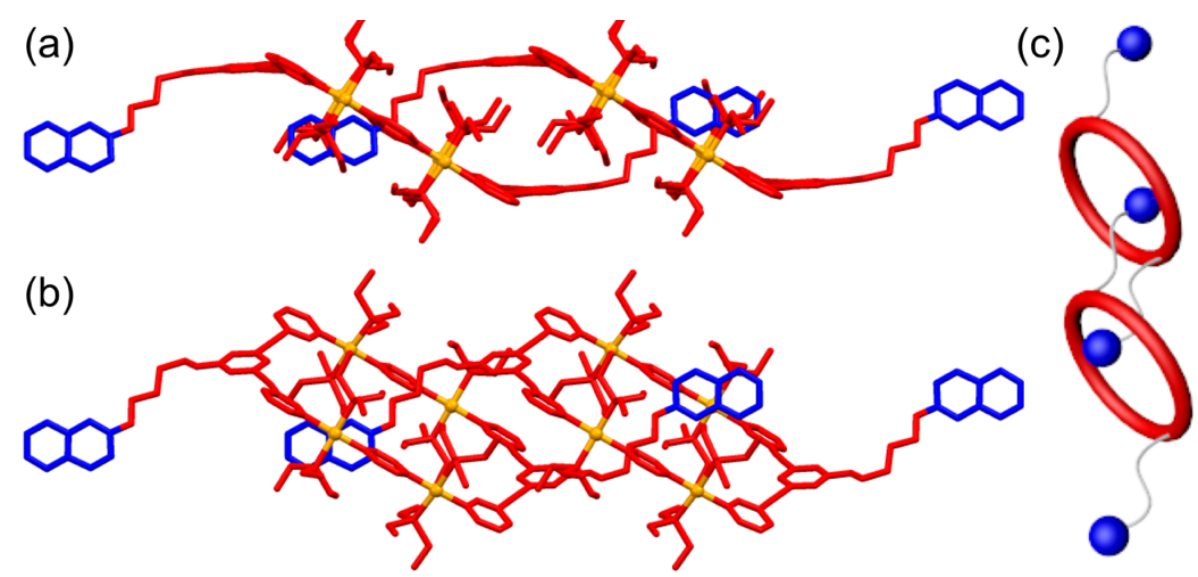

Figure S11. (a, b) Two views of the assembled single crystal produced by the host-guest complexation of 1. (c) Cartoon representation of the host-guest complexation of monomer 1. Hydrogen atoms are omitted for clarity.

5. 2D NOESY NMR spectrum of metallacycle 1.

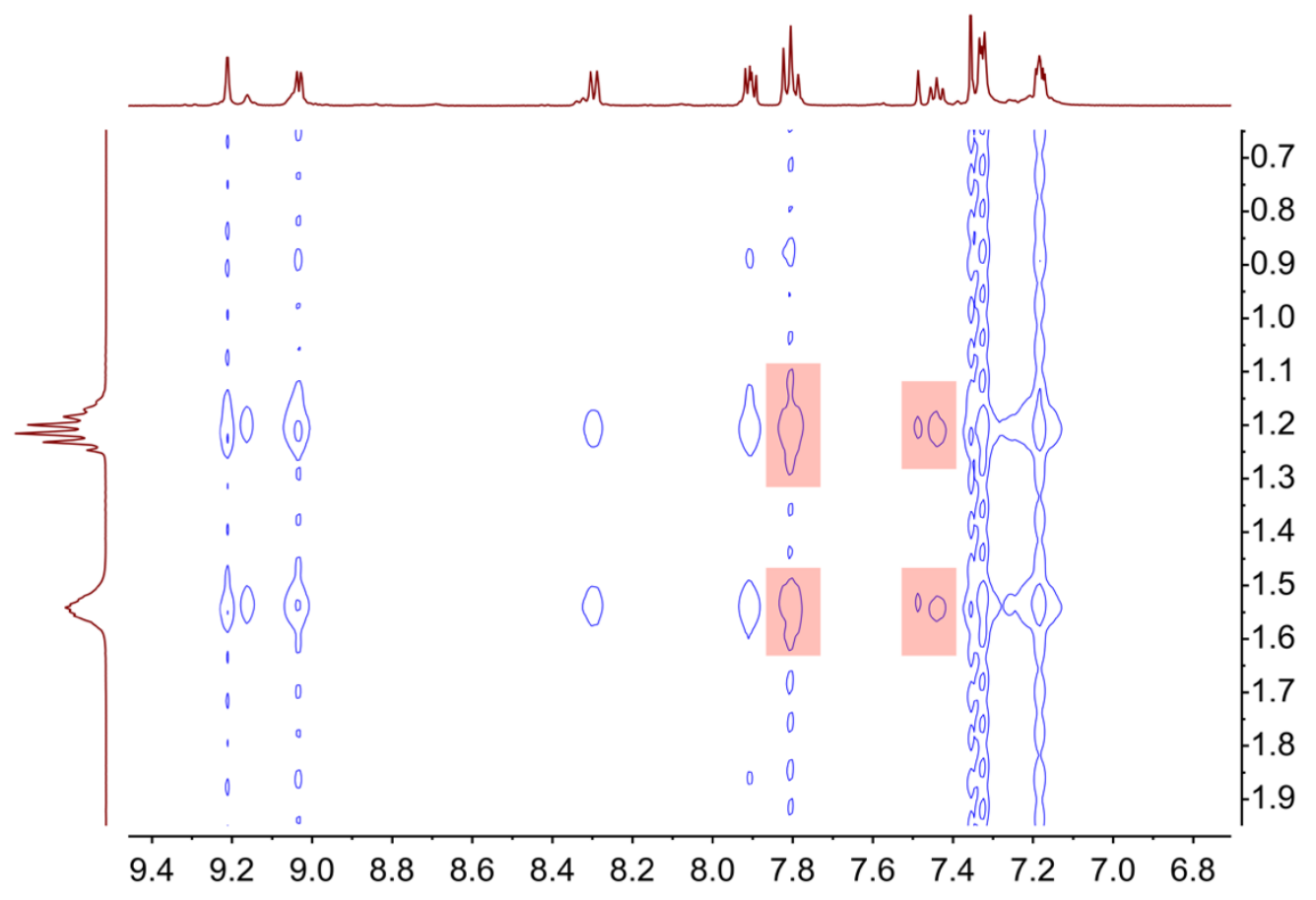

Figure S12. Partial 2D NOESY NMR (500 MHz, acetone- $\left.d_{6}, 298 \mathrm{~K}\right)$ spectrum of a solution of 1 (1.00 $\mathrm{mM})$. 
6. DLS study of the assemblies of monomer 1.
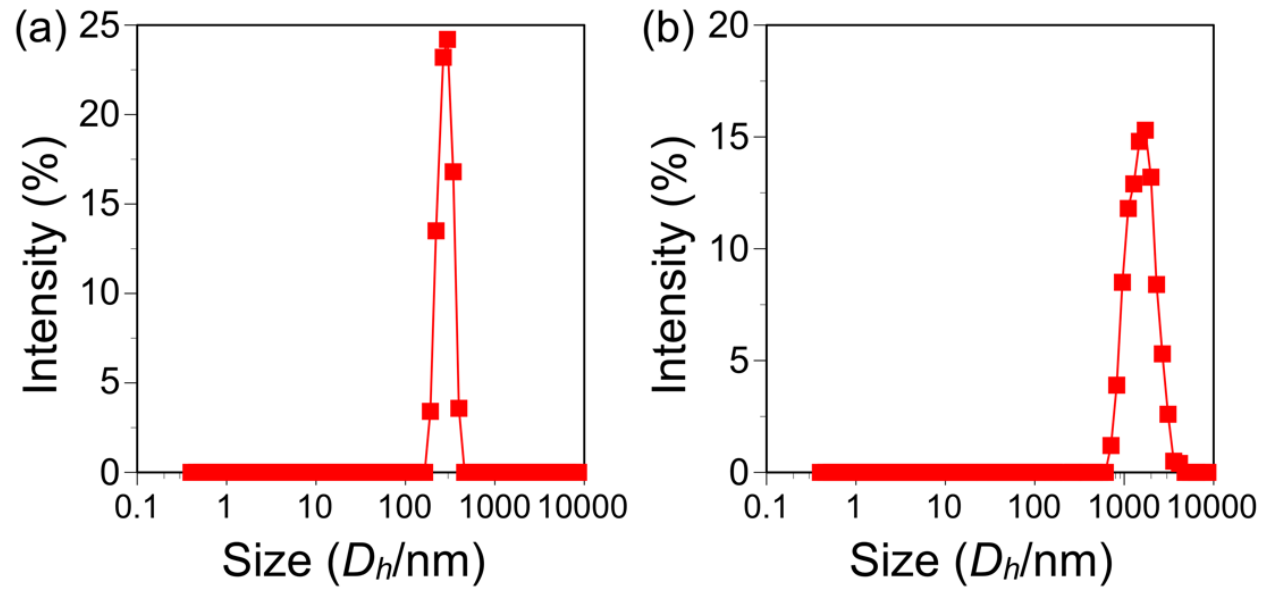

Figure S13. Size distribution of assemblies of 1 formed at different concentrations of 1 (a) $1.00 \mathrm{mM}$ and (b) $60.0 \mathrm{mM}$.

7. Self-assembled single-crystal structure of metallacycle 1.
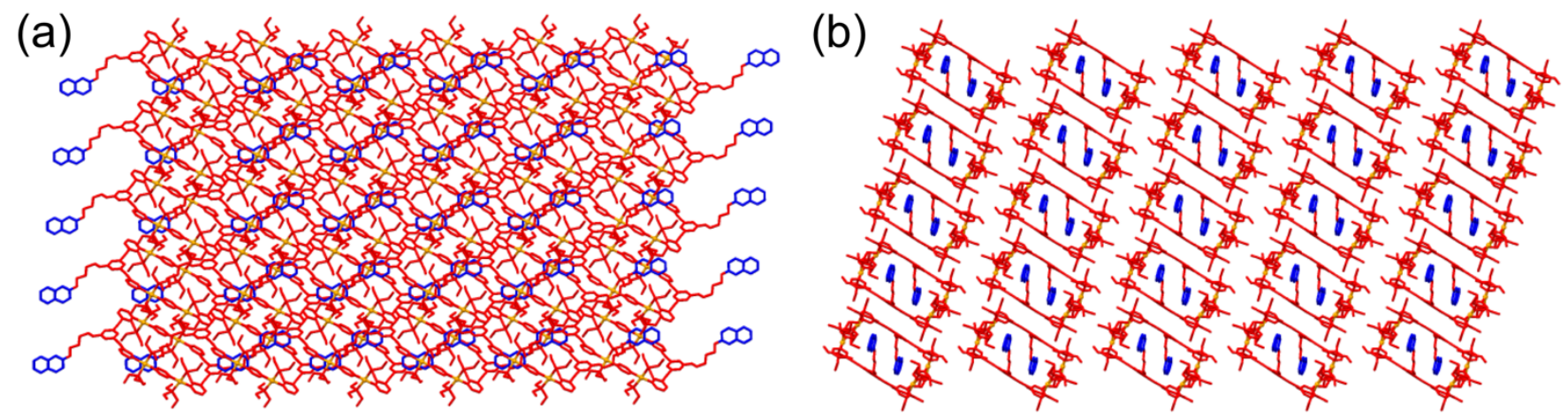

Figure S14. Two views of the single-crystal packing structure of the linear supramolecular polymer of monomer 1. Hydrogen atoms are omitted for clarity.

\section{X-ray crystal data for metallacycle 1}

Crystal Structure Determination: Single-crystal X-ray diffraction data was collected on a Nonius Kappa CCD diffractometer equipped with Mo K-alpha radiation $(\lambda=0.71073 \AA)$ and a BRUKER APEXII CCD. Throughout data collection, the crystal was cooled to 103(2) K with an Oxford Cryosystem. The APEX3 software suite was used to manage data collection, reduction (SAINT V8.38A1), absorption correction by 
the Multi-scan method (SADABS), structure determination via direct methods (SHLEXT) and model refinement (SHELXL). All non-hydrogen atoms were refined anisotropically and all hydrogen atoms were refined with isotropically with their positions constrained to their carriers. Platon Squeeze was used to account for regions of heavily disordered solvent that could not be modlled. The crystal structure was deposited into the Cambridge Structural Database, deposition 1906901.

Crystallographic data: rhombohedral prism, clear and colorless, $0.07 \times 0.200 \times 0.500 \mathrm{~mm}$, $\mathrm{C}_{128} \mathrm{H}_{180} \mathrm{~N}_{4} \mathrm{O}_{4} \mathrm{P}_{8} \mathrm{Pt}_{4}, 4\left[\mathrm{CF}_{3} \mathrm{O}_{3} \mathrm{~S}\right], F W 3463.15$, space group $\mathrm{P}-1, \mathrm{a}=12.0369(6) \AA, \mathrm{b}=15.4579(7) \AA, \mathrm{c}=$ $22.5390(11) \AA, \alpha=85.802(2)^{\circ}, \beta=74.887(2)^{\circ}, \gamma=82.736(2)^{\circ}$, volume $=4012.6(3) \AA 3, Z=1, D c=1.433$

$\mathrm{g} \mathrm{cm}^{-3}, T=103(2) \mathrm{K}, \mu=3.62 \mathrm{~mm}^{-1}, 170,740$ measured reflections, 25,178 independent reflections, 862 parameters, 283 restraints, $F(000)=1732.0, R_{(\mathrm{int})}=0.0348, R_{1}=0.0366[I>2 \sigma \mathrm{I}] / 0.0880[\mathrm{ALL}], \mathrm{w} R_{2}=$ 0.1033 (all data), max. residual density $3.279 \mathrm{e} \bullet \AA^{-3}$, and goodness-of-fit $\left(F^{2}\right)=1.086$. CCDC 1906901.

\section{References:}

S1. Schmidt, A.; Molano, V.; Hollering, M.; Pçthig, A.; Casini, A.; Kühn, F. Evaluation of New Palladium Cages as Potential Delivery Systems for the Anticancer Drug Cisplatin. Chem.-Eur. J. 2016, 22, 2253-2256.

S2. Manna, J.; Kuehl, C. J.; Whiteford, J. A.; Stang, P. J.; Muddiman, D. C.; Hofstadler, S. A.; Smith, R. D. Nanoscale Tectonics: Self-Assembly, Characterization, and Chemistry of a Novel Class of Organoplatinum Square Macrocycles. J. Am. Chem. Soc. 1997, 119, 11611-11619. 